
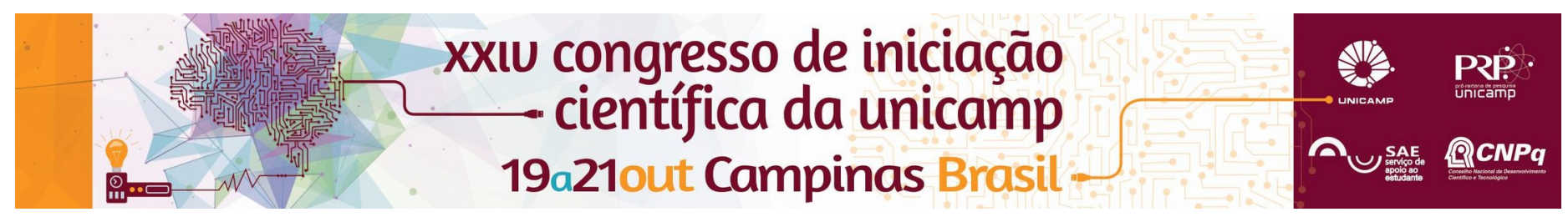

\title{
Controle Estatístico de Processos (CEP): Teoria e Prática
}

\section{Beatriz A. de Paula*, Edson G. P. da Silva*, Lucas C. Townsend*, André F. de Angelis}

\section{Resumo}

O Controle Estatístico de Processos é uma importante ferramenta para a qualidade na indústria. Neste projeto, foram vistos os fundamentos e as técnicas do CEP, a partir de atividades práticas feitas com materiais de baixo custo e instrumentos de precisão. Foi feita uma análise crítica dos dados medidos, dos valores calculados e do emprego da técnica. Foram obtidas cartas de controle derivadas das medições, posteriormente revisadas quanto a nãoconformidades segundo os critérios usuais da indústria. O resultado final foi um aprendizado profundo de estatística e análise de dados, complementado pela experiência em ambiente universitário e software livre.

\section{Palavras-chave:}

Qualidade na Indústria, Análise estatistica, Metrologia

\section{Introdução}

Os objetivos deste projeto foram estudar os fundamentos matemáticos do CEP e mostrar seu uso na indústria como ferramenta de controle de qualidade; comparar o referencial teórico e a prática, indicando situações de uso indevido da ferramenta, notadamente quando as propriedades estatísticas das distribuições não são satisfeitas.
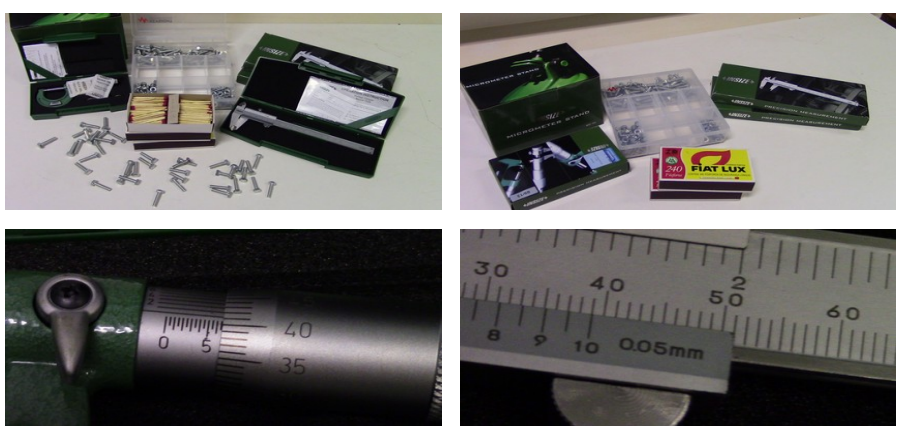

Figura 1. Materiais e instrumentos usados no projeto.

Os bolsistas estudaram o tema via levantamento bibliográfico e pesquisas na Internet, apresentaram e discutiram suas conclusões, efetuaram medidas de peças de madeira e metal com o uso de paquímetros e micrômetro (Fig. 1). Tabularam os dados em planilhas em Linux, gerando cartas de controle de média e ampliture, e verificaram a conformidade dos processos. Analisaram os dados e realizaram os testes de aderência em relação à distribuição Gaussiana. Obtiveram um aprendizado teórico e prático sobre estatística, processos produtivos e controle de qualidade.

\section{Resultados e Discussão}

Os resultados do projeto são classificados em dois grupos: teóricos e operacionais. No primeiro, estão os estudos e discussões realizadas, com o consequente aprendizado de técnicas e contato com uma análise crítica de séries de dados. No segundo, estão as medições, feitas com precisão de $0,05 \mathrm{~mm}$ :

Peças de madeira:

- espessura e comprimento de 480 palitos de fósforo;

\section{Peças metálicas:}

- altura e diâmetro da cabeça de 100 parafusos;

- espessura e diâmetro externo de 100 porcas;

- espessura e diâmetro externo de 100 arruelas.

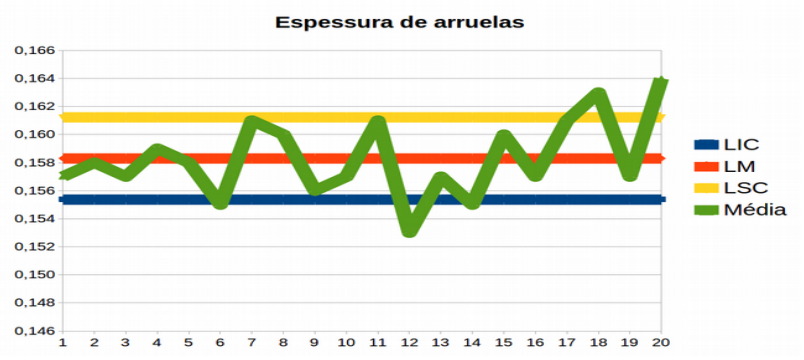

Figura 2. Exemplo de carta CEP.

Ainda nos resultados operacionais, tem-se as cartas CEP (Fig. 2), sua análise e verificação de nãoconformidades e os testes de aderência à Gaussiana, pelos métodos visual e qui-quadrado.

\section{Conclusão}

O objetivo do projeto foi alcançado. Os bolsistas aprenderam sobre a aplicação e importância do CEP nas empresas, entenderam os conceitos da estatística e realizaram cartas de controle com dados levantados por eles mesmos. Além disso, frequentaram palestras e se familiarizaram com o ambiente da Uncamp.

\section{Agradecimentos}

Ao monitor Petrus R.C.D.S. Araujo; aos financiadores CNPq e FAEPEX.

Bertulucci Silveira, Cristiano ; Cartas de Controle; disponível em <http://www.citisystems.com.br/cartas-de-controle/> acesso em abril de 2016.

Farias, Alfredo Alves de \& Soares, José Francisco - Introdução à Estatística. $2^{a}$ edição Editora LTC.

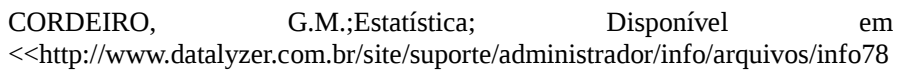
/78.htm> acesso em maio de 2016.

CAVALCANTE, Romirys; Medidas de tendência central; Disponível em $<$ http://www.vivendoentresimbolos.com/2012/08/medidas-de-tendenciacentral-media-moda.html> acesso em maio de 2016. 